DOI: https//doi.org/10.13037/ci.vol22n49.7567

\title{
O desenvolvimento de iniciativas de Democracia Digital pela sociedade civil e por GovTechs: uma comparação entre as plataformas Mudamos, Colab e Panela de Pressão
}

\author{
The development of Digital Democracy initiatives by civil society and by GovTechs: a \\ comparison between the Mudamos, Colab and anela de Pressão platforms
}

\section{Samuel Barros ${ }^{a}$}

Orcid: https://orcid.org/0000-0001-8931-3262.

Carla Rodrigues ${ }^{b}$

Orcid: https://orcid.org/0000-0002-2988-7464

Recebido em: 18/12/2020. Aprovado em: 11/05/2021

Resumo

Este artigo tem como objetivo estudar organizações da sociedade civil e empresas (GovTechs) que desenvolvem iniciativas de democracia digital para a promoção da participação on-line. Tomamos por objeto três iniciativas: 1) Mudamos; 2) Colab.re; e 3) Panela de Pressão. A avaliação considerou cinco dimensões: 1) recursos tecnológicos, 2) modos de participação on-line, 3) atores envolvidos, 4) objetivos políticos das iniciativas, e 5) a captação de recursos. Os resultados apontam para a importância do arranjo organizacional para entender o desenvolvimento de iniciativas bem-sucedidas de democracia digital.

Palavras-chave: Democracia Digital. Sociedade Civil. GovTechs.

\section{Introdução}

Nos últimos anos temos observado que organizações da sociedade civil e empresas desenvolveram plataformas de democracia digital com o objetivo de a) fomentar a participação po

\footnotetext{
a Professor adjunto da Universidade Federal do Recôncavo da Bahia (UFRB). Bahia/Brasil. E-mail: samuel.barros@ufrb.edu.br

b Universidade Federal da Bahia (UFBA). Bahia/Brasil. E-mail: carla.rodrigues@inctdd.org
}

Keywords: Digital Democracy. Civil Society. GovTech. 
r meios não estatais, e, particularmente no caso de empresas, para b) vender as soluções tecnológicas para entes públicos ou c) usar essas iniciativas como portfólio para conseguir novos clientes. Nas três situações, o poder de mobilização social por meios digitais para fins públicos e políticos, se adequa aos interesses e objetivos organizacionais sob a estratégia de mediação entre a sociedade e o Estado. Diante desse cenário de atores diversos, essa pesquisa parte da seguinte questão: como os arranjos organizacionais podem nos ajudar a entender o desenho tecnológico, político e econômico dessas novas iniciativas?

Nos anos recentes, duas plataformas em particular têm recebido a atenção dos pesquisadores brasileiros, a VotenaWeb (LUVIZOTTO, 2016; ROSSETTO, CARREIRO, 2012; SANTOS; NETO; SOUZA, 2017) e a Colab (SILVA; POLICARPO, 2014; SANTOS; NETO; SOUZA, 2017). Neste estudo, entendemos as plataformas digitais como dispositivos que atuam na mediação do cotidiano e podem ser descritas como infraestruturas baseadas em hardware e software que são alimentados por dados. As plataformas se tornaram uma dimensão fundamental para a constituição do espaço e do tempo, bem como do novo sistema de produção e reprodução do capital, têm lógicas próprias - e quase sempre particulares - de fabricação, logística e design, fornecendo a paisagem básica sobre a qual o resto da indústria opera (D'ANDRÉA, 2020; SRNICEK, 2017). Defendemos, contudo, que faltam olhares mais abrangentes e estudos comparativos entre plataformas desenvolvidas por organizações com diferentes arranjos. Esse enfoque, é importante destacar, justifica-se por se tratar de uma dimensão fundamental para o desenvolvimento de iniciativas que têm sido, salvo comentários rápidos em trabalhos com outros enfoques, ignoradas pela comunidade de pesquisa em democracia digital no Brasil. Por democracia digital, entendemos o emprego de tecnologias digitais com o objetivo de corrigir, incrementar ou incorporar novos procedimentos ao processo político no sentido de melhor atender a um ou mais princípios da democracia, tais como, participação política, transparência pública, informação política qualificada, deliberação pública, entre outros a depender do modelo de democracia que se adote (DAHLBERG, 2011; GOMES, 2011; GRÖNLUND, 2003). Assim, além da Colab, uma plataforma desenvolvida por uma GovTech que tem sido muito investigada em trabalhos acadêmicos, analisamos os casos do aplicativo Mudamos, desenvolvido pelo Instituto de Tecnologia e Sociedade do Rio de Janeiro (ITS Rio), financiada pelo Google mediante o Desafio de Impacto Social 2016, e Panela de Pressão, desenvolvida pela rede Nossas Cidades, uma organização nacional 
que procura fomentar a participação em nível municipal. A escolha desses casos foi orientada pela preocupação de termos diferentes formas de desenho e financiamento das organizações estudadas.

\section{De Obama às GovTechs: colaboração?}

Organizações da sociedade civil e de empresas podem colaborar com o desenvolvimento de projetos que resolvam problemas da administração pública (e-gov) e/ou para o fortalecimento da democracia (democracia digital). Em nível global, esse movimento foi impulsionado pela administração Barack Obama nos Estados Unidos. A ação mais importante neste sentido foi o lançamento, em 2010, da plataforma Challenge (www.challenge.gov) para promover a colaboração de indivíduos, organizações sociais e empresas, inclusive com prêmios em dinheiro, para a resolução de problemas enfrentados pela administração federal americana.

Beth Noveck, que trabalhou na administração Obama entre 2009 e 2011 na frente para a promoção de governo aberto, autora do hoje clássico Wiki government: How technology can make government better, democracy stronger, and citizens more powerful (2009), argumenta, em que pese a contribuição histórica das teorias e práticas do campo da participação política, que as tecnologias digitais nos dariam a possibilidade de pensar em formas menos custosas e mais eficientes para engajar os cidadãos. Poderíamos mesmo, para além da participação, pensar em formas de a sociedade efetivamente colaborar na resolução de problemas. Noveck cita a conhecida dinâmica de trabalho coletivo das wikis ou a colaboração a partir da divisão das tarefas em partes.

O Brasil, apesar de ser um dos sócios fundadores da Open Government Partnership (OGP), uma iniciativa multilateral voltada para promoção de práticas de governo aberto ao redor do mundo, e ter aprovado de forma pioneira o Marco Civil da Internet (BARROS, 2016), não tem incentivado - ao menos se considerarmos o governo em nível federal - iniciativas da sociedade civil ou de empresas. Em que pese a política de dados abertos ter como um dos argumentos a possibilidade de uso destes por parte de desenvolvedores (PINHO, 2019), não há uma diretiva, orientação ou incentivo mais sistemático para a colaboração entre governos, organizações da sociedade civil ou empresas.

Organizações da sociedade civil, movimentos sociais, coletivos, universidades e fundações, percebendo o potencial das tecnologias digitais, têm investido no estudo e 
desenvolvimento de soluções digitais. Nesse ambiente é comum a publicação dos códigos das aplicações para que outros possam implementar a mesma iniciativa em outro contexto ou usar como parte de aplicações novas. Esses atores, inclusive, não hesitam em colaborar com governos em situações que estes demandam a solução de algum problema. Temos visto a proliferação de encontros de especialistas nomeados como hackathons para a resolução de problemas da esfera da cidadania, relacionados ao estado ou não (DOIMO; 2019; MITOZO, 2014).

Ao mesmo tempo, ao redor do mundo, inclusive no Brasil, empresas têm se movimentado para criar produtos e soluções digitais para governos. Essas empresas têm se nomeado coletivamente como GovTechs. No Reino Unido, existe até mesmo um fundo de investimentos especializado em startups desse setor: o Public.io, que organiza eventos, publicações e faz lobby para que governos adotem soluções digitais. No Brasil, existe uma organização com atuação semelhante chamada BrazilLab, que apresenta na cartela de clientes prefeituras de capitais como São Paulo, Belo Horizonte e Curitiba.

Essas iniciativas de abertura do governo para que empresas desenvolvam soluções para os serviços públicos está em linha com o argumento de O'Reilly (2010) de que os governos devem entender-se como uma plataforma para incentivar que cidadãos e empreendedores desenvolvam aplicações para aperfeiçoar os serviços públicos existentes, atender novas demandas dos cidadãos e até mesmo desenvolver soluções para questões que ainda não tenham emergido.

O VotenaWeb, por exemplo, foi desenvolvido por uma empresa e tem como objetivo dar visibilidade a projetos de lei da Câmara dos Deputados e do Senado Federal, destacando a opinião de deputados e senadores sobre a matéria, bem como viabiliza a expressão da opinião dos usuários por meio de votos e comentários. Mendonça e Pereira (2011) estudaram três fóruns de discussão da plataforma VotenaWeb e chegaram à conclusão de que essa plataforma traz contribuições importantes para a deliberação pública, o que é valorado a partir do entendimento de que esta é uma demanda normativa da democracia.

O caso do VotenaWeb é importante para a comunidade brasileira de pesquisa em democracia digital especialmente porque marca a possibilidade de iniciativas de empresas desenvolverem, implementarem e gerirem iniciativas tecnologicamente robustas e que apresentem alto teor democrático, para usar os temos de Gomes (2011). O entendimento dos novos arranjos organizacionais de atores não-estatais que tornam possíveis iniciativas como o VotenaWeb é, então, o objeto de nossa curiosidade. $\mathrm{Na}$ 
última década, apesar das mudanças políticas em direção ao autoritarismo, desenvolveuse um ecossistema no qual organizações civis e empresas desenvolvem aplicações que têm sido usadas em grande escala. Cabe, então, questionarmos as implicações de cada tipo de organização.

\section{Metodologia}

Neste estudo, analisamos três iniciativas de tipos de organizações diferentes. A iniciativa Mudamos foi desenvolvida por um think tank chamado Instituto de Tecnologia e Sociedade do Rio de Janeiro (ITS Rio), a Colab foi desenvolvida por uma empresa GovTech e o aplicativo Panela de Pressão por uma organização da sociedade civil. A comparação de três casos distintos tem a vantagem de permitir a comparação entre características distintas e a desvantagem de não permitir uma análise mais sistemática e aprofundada de características específicas de cada caso, como seria possível se estudássemos apenas um caso.

Os casos foram selecionados de modo a garantir diferentes desenhos organizacionais, uma vez que o objetivo é estudar a influência desse variável. Contudo, o pequeno número de casos e o desconhecimento quanto às características de toda a população de iniciativas desse tipo não nos permite generalizar os resultados produzidos por esta pesquisa. O esforço de pesquisa continua importante, contudo, para uma primeira exploração de uma dimensão do fenômeno que é, em grande medida, ignorado pela pesquisa acadêmica.

Para a análise das iniciativas, construímos uma grade de cinco dimensões analíticas (descritas no Quadro 1): a) os recursos tecnológicos utilizados, o que inclui as funcionalidades e soluções tecnológicas dos respectivos sites e aplicativos atualizados; b) as formas de participação on-line possíveis mediante as plataformas; c) os atores que, de alguma forma, estão envolvidos no desenvolvimento e uso das iniciativas; d) os objetivos políticos das iniciativas, especialmente aqueles em relação a políticas públicas e outras ações por parte do Estado; e) as estratégias para a captação de recursos visando o desenvolvimento e manutenção das plataformas.

Quadro 1 - Critérios das organizações para avaliar a participação política.

\begin{tabular}{l|l} 
Dimensões & Descrição
\end{tabular}




\begin{tabular}{|l|l|}
\hline $\begin{array}{l}\text { Recursos } \\
\text { tecnológicos }\end{array}$ & $\begin{array}{l}\text { Os recursos tecnológicos empregados para o desenvolvimento dos sites e aplicativos } \\
\text { das organizações. Serão considerados a linguagem e o design tendo como horizonte a } \\
\text { experiência do usuário, destacando-se os recursos para a promoção da participação } \\
\text { política. }\end{array}$ \\
\hline $\begin{array}{l}\text { Modos de } \\
\text { participação } \\
\text { on-line }\end{array}$ & $\begin{array}{l}\text { Os sites e aplicativos podem engajar os usuários através de mecanismos variados, a } \\
\text { exemplo de fóruns, comentários, votações, convocação para manifestação em outros } \\
\text { ambientes, entre outros. Essa dimensão é importante para o estudo da organização } \\
\text { particularmente naquilo que diz respeito ao recebimento e destinação do input recebido } \\
\text { por parte do cidadão. Interessa entender como a plataforma faz a mediação entre a } \\
\text { participação e a influência política no Estado e em outros atores. }\end{array}$ \\
\hline $\begin{array}{l}\text { Atores } \\
\text { envolvidos }\end{array}$ & $\begin{array}{l}\text { Os tipos de atores que, de algum modo, se engajam através da plataforma, a exemplo } \\
\text { dos usuários cadastrados, organizações da sociedade civil e servidores públicos. }\end{array}$ \\
\hline $\begin{array}{l}\text { Objetivos } \\
\text { políticos }\end{array}$ & $\begin{array}{l}\text { O objetivo da plataforma, expresso sob a forma de documentos ou pelas características } \\
\text { da iniciativa. Esperamos avaliar qual é o resultado esperado da ação política dos } \\
\text { usuários da plataforma. Essa variável é importante para questionar possiveis } \\
\text { incoerências entre objetivos declarados e o desenho da plataforma, mas também é um } \\
\text { marco importante para a avaliação do sucesso da plataforma por parte de todos os } \\
\text { atores. }\end{array}$ \\
\hline $\begin{array}{l}\text { Captação de } \\
\text { recursos }\end{array}$ & $\begin{array}{l}\text { Métodos para captar recursos, investimentos públicos ou privados, para financiar o } \\
\text { desenvolvimento das plataformas. Tais recursos podem ser alcançados por editais } \\
\text { públicos, contratação para a prestação de serviço, financiamento por parte de fundações } \\
\text { e empresas, recursos próprios, entre outras. }\end{array}$ \\
\hline
\end{tabular}

Fonte: Elaboração dos autores.

A coleta de dados se deu basicamente a partir de informações e documentos divulgados pelas próprias iniciativas em análise, bem como a partir da observação direta, por parte dos pesquisadores, das interfaces acessíveis por um usuário comum. Temos ciência de que esse segundo método de coleta de dados implicou no aumento de influência da subjetividade nos resultados, mas justamente por reconhecer esse risco procuramos descrever e fundamentar tanto quanto possível os nossos achados para que o leitor tenha melhores condições de interpretação.

\section{Resultados: os desenhos organizacionais e o desenvolvimento de iniciativas de democracia digital}

Cada uma das iniciativas foi analisada levando em conta as variáveis apresentadas no tópico anterior: 1) os recursos tecnológicos utilizados, 2) os modos de participação on-line possíveis mediante as plataformas, 3) os atores envolvidos, 4) os objetivos políticos das iniciativas, e 5) a captação de recursos. Na sequência, fazemos um esforço de sintetizar alguns achados a partir da comparação entre os casos. 


\subsection{Mudamos}

O Mudamos (www.mudamos.org) se apresenta como plataforma que pretende fazer com que cidadãos possam elaborar e assinar projetos de lei de iniciativa popular de forma segura e gratuita, ao tempo em que propõe solucionar dificuldades de coleta e verificação das assinaturas em papel, que antes eram realizadas em maior tempo e dependia de um parlamentar concordar e apresentar como sua iniciativa. Desse modo, aumentam as possibilidades de ação política por parte do cidadão. O Mudamos usa um recurso de participação reconhecido pela Constituição Federal de 1988: o projeto de lei de iniciativa popular. Para que um projeto de lei de iniciativa popular possa ser apreciado pelo Congresso Nacional, precisa das assinaturas de pelo menos $1 \%$ do eleitorado nacional, distribuído por pelo menos cinco estados com não menos dos três décimos por cento dos eleitores de cada um deles, como prevê a Constituição Federal, no seu artigo 61, $\S 2^{\circ}$. Assim, articular interessados em um determinado tema e conseguir assinaturas juridicamente válidas é o grande desafio que o Mudamos tenta alcançar.

Figura 1 - destaques dos projetos de lei de iniciativa popular.

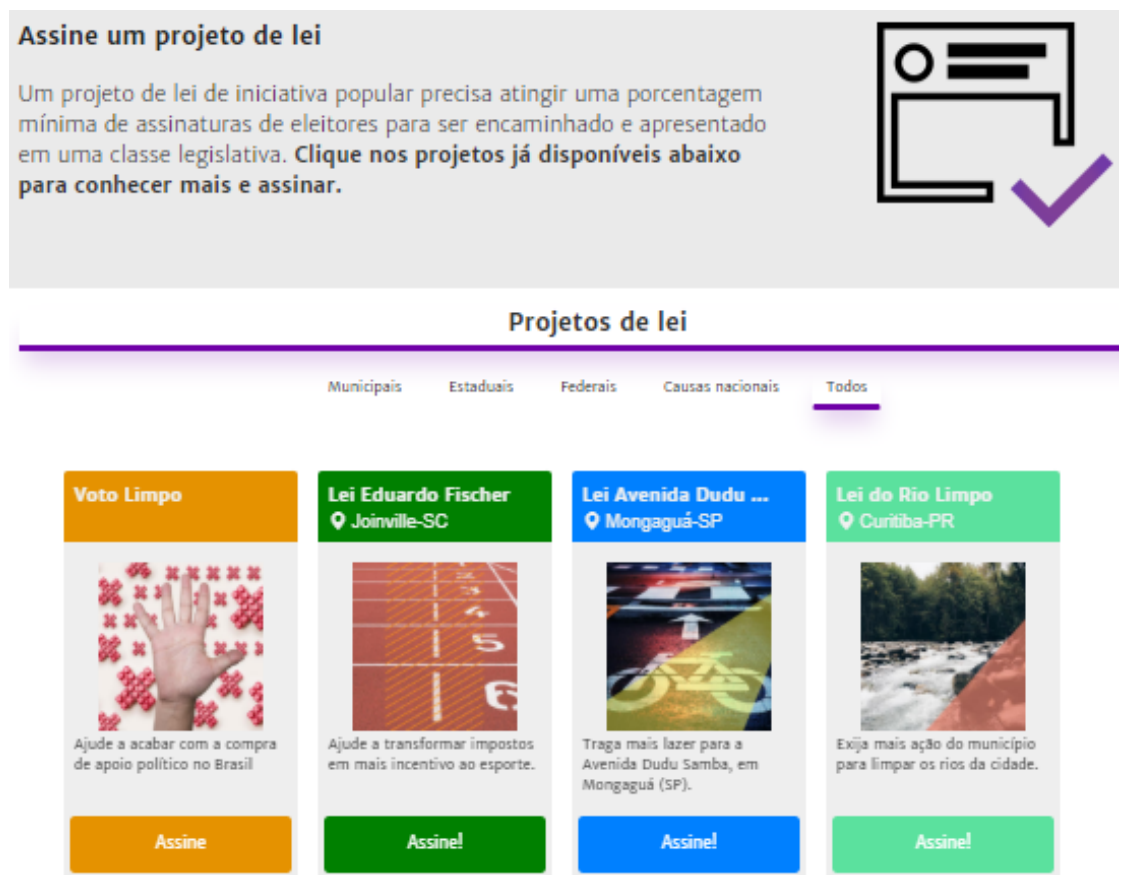

Fonte: Projetos de Lei Mudamos (2019) 
O site institucional direciona para o aplicativo móvel, uma vez que a assinatura de projetos de lei é possível apenas pelo celular. Uma vez no aplicativo, o usuário pode tomar conhecimento, assinar e propor projetos de lei. Para participar do Mudamos é preciso criar uma conta com e-mail pessoal. Nesse momento, são apresentados os termos de uso e a política de privacidade. Na ferramenta Fale Conosco, o usuário pode trocar experiências e articular-se com outros para a elaboração de projetos de leis.

Os projetos apresentados podem estar relacionados às esferas municipal, estadual, federal na categoria nacional. Para apresentar um projeto de lei é necessário ser usuário do aplicativo Mudamos, apresentar nome, texto do projeto em uma estrutura que se aproxima da norma legislativa (com capítulos, artigos e parágrafos) e informar se o projeto é voltado para a esfera nacional, estadual ou municipal. Para argumentar pela proposta, o usuário deve enviar um vídeo. Por fim, deve informar se conhece outro projeto aprovado similar à proposta apresentada. Todos os projetos de lei são disponibilizados para os usuários assinarem e acompanharem quantas assinaturas faltam para alcançar a meta (ver Figura 2).

Figura 2 - assinaturas e acompanhamento da meta do projeto de lei de iniciativa popular.

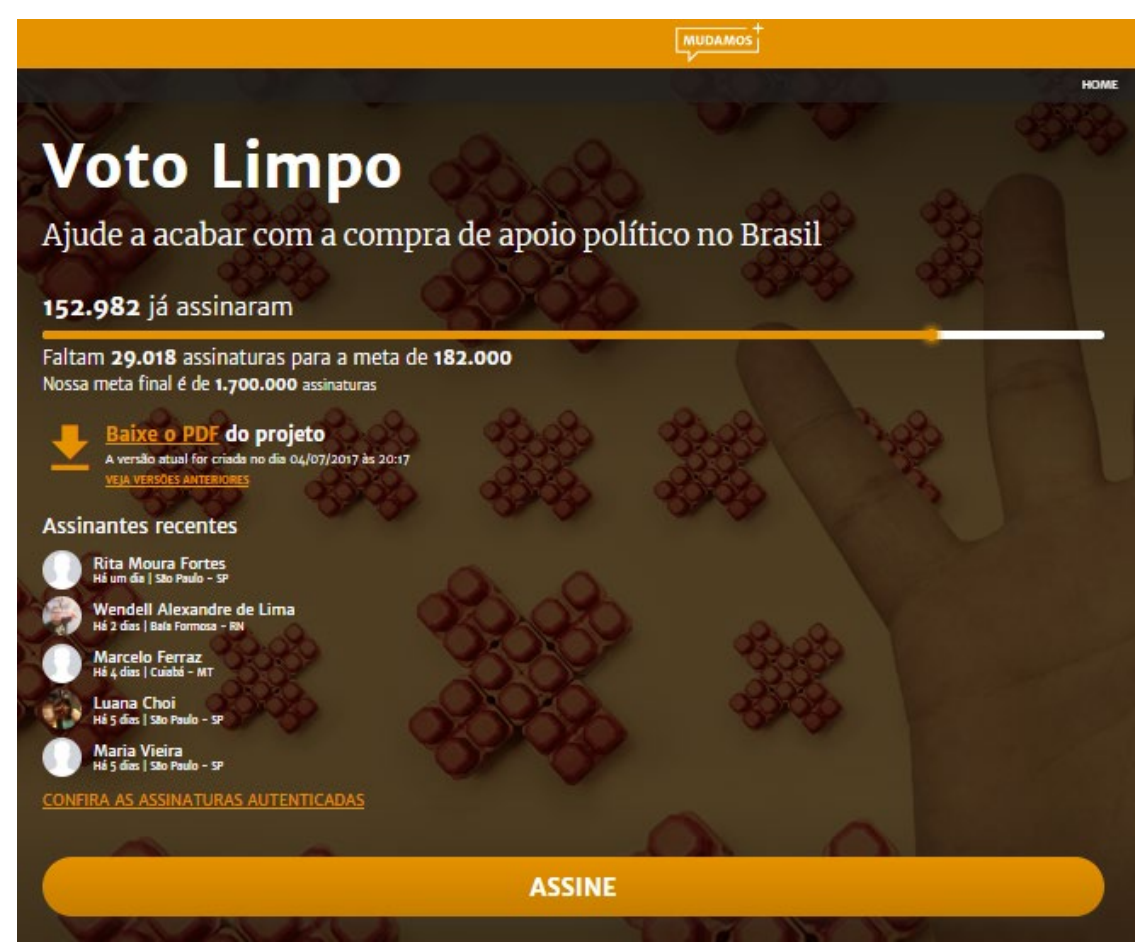

Fonte: Assinatura Mudamos, Voto Limpo (2019).

O apoio dos cidadãos é fundamental para conseguir a meta de assinaturas, por isso mesmo as estratégias de mobilização são tão importantes. Orientações sobre o 
processo de mobilização podem ser encontradas no guia (https://www.mudamos.org/mobilizacao), bem como materiais para serem distribuídos em ambientes on-line e panfletos e adesivos para impressão, além de um tutorial de estratégias para organização que aborda temas como: comunicação no espaço on-line, identificação de canais e públicos, como fazer vídeos e utilizar hashtags, construir contatos e estruturar encontros.

O objetivo é capacitar os usuários para mobilizar mais pessoas e, assim, conseguir as assinaturas para o projeto de lei de iniciativa popular. Destaque-se que a plataforma permite o compartilhamento com o Whatsapp, Instagram, Twitter, Tumblr, Facebook, Snapchat, Drive, Gmail e até mesmo em conexão via Bluetooth, além de conversão de conteúdos em PDF. Uma das estratégias de mobilização é o vídeo institucional; a finalidade da ferramenta é apresentar os objetivos do Mudamos por uma integrante da organização, e como os usuários podem se mobilizar para conseguir atrair o maior número de novos membros.

O Mudamos tem como principal subproduto a Virada Legislativa, desenvolvida em uma metodologia de educação e participação em eventos nas cidades brasileiras com o propósito de apresentar as etapas e auxiliar os cidadãos a escreverem um projeto de lei. Nessa funcionalidade é possível incluir voluntários dispostos a discutir problemas comuns e dar soluções possíveis.

O aplicativo foi desenvolvido pelo Instituto de Tecnologia e Sociedade (ITS Rio) com recursos do Desafio Google de Impacto Social 2016, o qual tinha como proposta declarada conectar as demandas sociais da sociedade civil com os atores responsáveis pela tomada de decisão. O aplicativo foi lançado em 30 de março de 2017 e a última atualização para o sistema Android no Google Play foi em 6 de setembro de 2019, e para $i O S$ no App Store em 8 de setembro de 2019. No total soma mais de 670 mil downloads na plataforma.

O espaço para dúvidas tem, entre outras informações gerais, explicações sobre o processo após o recolhimento de assinaturas para que um projeto de lei de iniciativa popular possa ser aprovado, a proximidade de um projeto de atingir a meta necessária de assinaturas, como é possível garantir a veracidade das assinaturas no aplicativo e a validade jurídica das assinaturas eletrônicas. Cabe citar que tal sistema é viabilizado pela tecnologia blockchain. 


\begin{tabular}{|l|l|}
\hline \multicolumn{1}{|c|}{ Dimensões } & \multicolumn{1}{c|}{ Descrição } \\
\hline $\begin{array}{l}\text { Recursos } \\
\text { tecnológicos }\end{array}$ & $\begin{array}{l}\text { Site institucional; aplicativo Android e iOS; cadastro por e-mail ou vinculado à } \\
\text { conta do Facebook; compartilhamento em rede: Facebook e Twitter. Códigos no } \\
\text { GitHub; segurança de tecnologia blockchain; é possível compartilhar cada um } \\
\text { dos projetos de lei mediante: Whats App, Instagram, Twitter, Tumblr, Gmail, } \\
\text { Facebook, SMS, Snapchat, Google Drive e Bluetooth. }\end{array}$ \\
\hline $\begin{array}{l}\text { Modos de } \\
\text { participação on-line }\end{array}$ & Apresentação de projetos de lei, assinatura de projetos, envio de projetos. \\
\hline Atores envolvidos & ITS Rio, Google, indivíduos com registro no aplicativo. \\
\hline Objetivos políticos & $\begin{array}{l}\text { Coleta de assinaturas para projetos de lei de iniciativa popular, dar visibilidade } \\
\text { para o processo legislativo. }\end{array}$ \\
\hline Captação de recursos & Financiamento pelo Desafio Google de Impacto Social 2016. \\
\hline
\end{tabular}

Fonte: Elaboração dos autores.

\subsection{Colab}

A Colab (https://app.colab.re) se apresenta como uma empresa emergente (startup). Iniciado em 2013, recebeu investimento de um fundo internacional (Media Development Investment Fund). Em 2015, fechou um contrato com a organização social Comunitas para atender as cidades de São Paulo e Pelotas (Rio Grande do Sul). Também em 2015, firmou contrato com a prefeitura de Teresina, e atualmente desenvolve trabalhos para as cidades de Recife, Ipojuca (PE), Niterói (RJ), Mesquita (RJ), Maceió, Aracaju, Cruz Alta (RS), Santo André (SP) e Juiz de Fora (MG). Além do uso da plataforma, a Colab anuncia que presta consultorias de forma presencial ou por Skype.

A atuação da Colab é reconhecida por vários prêmios oferecidos por fundações e entes públicos. Em 2013, a Colab foi eleita como o melhor aplicativo urbano pela New Cities Foundation devido à conquista do prêmio App My City. Em 2015, como startup com maior impacto social pelo Banco Interamericano de Desenvolvimento. Em 2018, foi uma das três startups vencedoras da $2^{\mathrm{a}}$ edição do PITCH GOV, iniciativa para promover a inovação do governo do estado de São Paulo.

A Colab também é uma das iniciativas de democracia digital mais estudadas do Brasil. Uma pesquisa no Google Acadêmico pelos termos "Colab" AND "aplicativo" retorna 279 resultados. A maior parte dos estudos realizados, contudo, dedica-se ao estudo da interface e/ou das implicações do aplicativo para a participação política local 
(SILVA; POLICARPO, 2014; SANTOS; NETO; SOUZA, 2017). Desconhecemos estudos com a mesma abordagem que este.

Além do website, existe um aplicativo com versão para Android e iOS. O aplicativo foi lançado em 6 de março de 2013 e possui mais de 100 mil downloads e mais de 2 mil avaliações sobre o funcionamento da ferramenta em cada plataforma. É importante destacar que, por se tratar de uma plataforma voltada para os problemas vividos nas cidades, a mobilidade do celular é um elemento que precisa ser destacado. A câmera e o GPS acoplados permitem a produção de fotografias e a marcação da localização no mesmo momento em que experiência se dá.

Existem duas formas de acessar a plataforma Colab, como usuário após cadastro ou como ator político/gestor público. Nesse último caso, o acesso é direcionado para a interface Colab.gov, através da qual é possível gerir as demandas feitas pelos usuários e o fluxo de informações entre diferentes secretarias e servidores. A plataforma informa que mais de 2.000 agentes públicos usaram essa interface nos últimos cinco anos.

Para o usuário participar de forma ativa é necessário enviar fotografias pela funcionalidade “+Publique", anexar a imagem junto à legenda, adicionar o endereço com rua, bairro e cidade onde a imagem foi feita. A maioria das publicações é de reclamações sobre a via urbana. É possível também usar hashtags, o que facilita a interação entre os usuários e a identificação de problemas comuns.

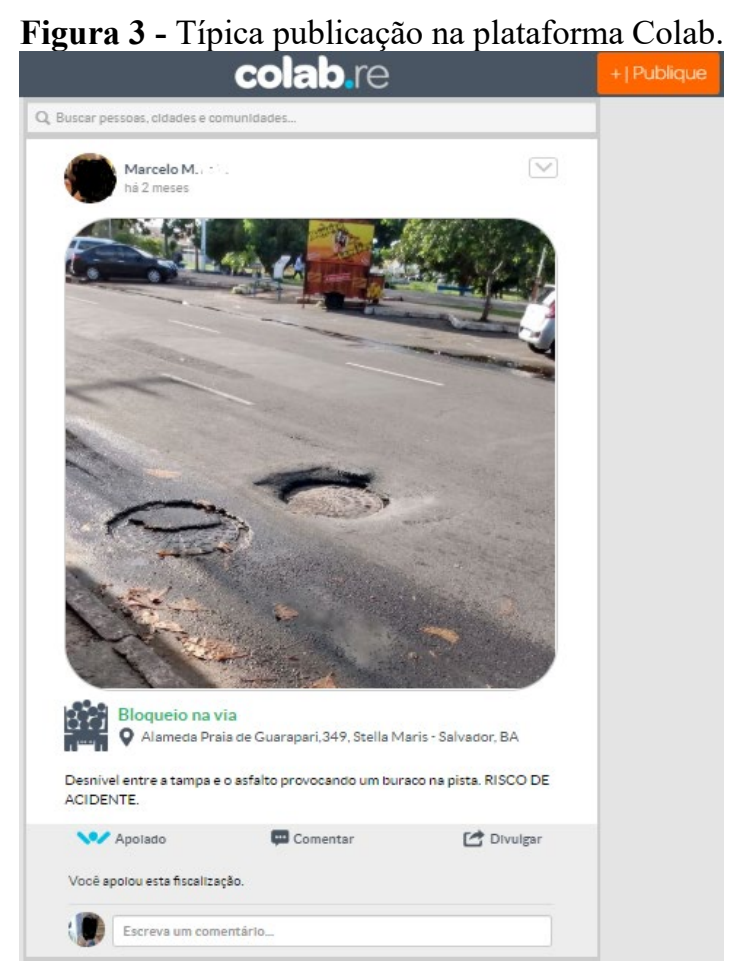

Fonte: Colab App Store (2019) 
Cada publicação pode também receber comentários e ser compartilhada por outros usuários. A plataforma tem integração com o Twitter, LinkedIn, Facebook e Google+. Nessa função, a Colab pode ser entendida como um meio de dar visibilidade para determinados problemas e, assim, pressionar os agentes públicos a resolvê-los. Cada perfil pessoal possui missões (campanhas para engajamento), conquistas (como colaborar mais para a cidade) e ranking de cidadãos mais engajados na plataforma com posição entre as pessoas da cidade e país. O aplicativo envia notificações para alertar quanto a novos projetos, comentários e apoio, além de alertas em caso de o usuário ficar ausente do aplicativo por muito tempo.

Figura 4 - Atuação da Colab: assuntos mais reivindicados pelos usuários residentes de Salvador.

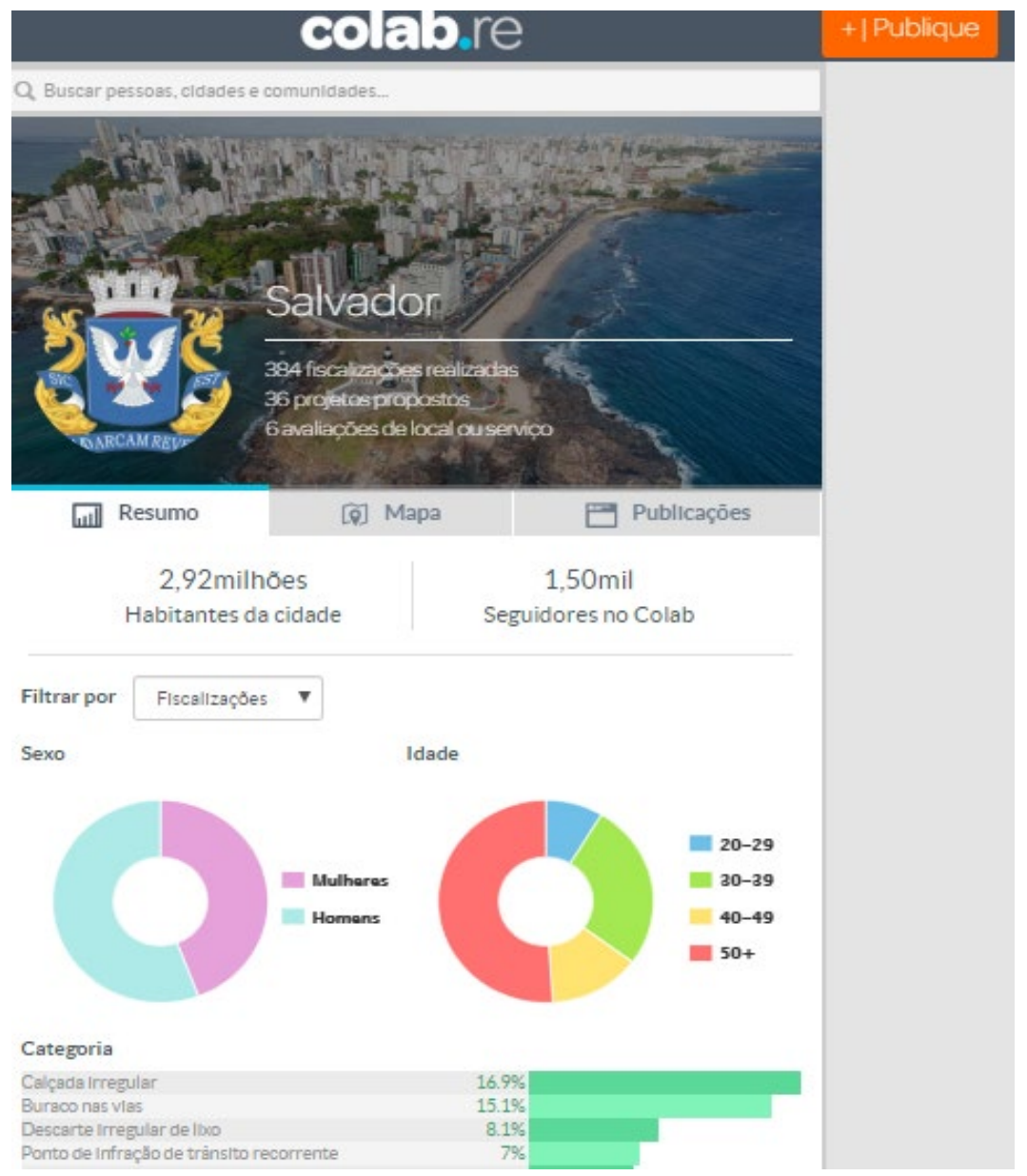

Fonte: Aplicativo Colab (2019)

Como extensão do site institucional, o blog Colab trata de assuntos públicos, a exemplo da Agenda 2030 sobre a fome e agricultura sustentável. O blog também está interligado às redes sociais digitais (Twitter, Facebook, LinkedIn, Whatsapp, Telegram 
e Instagram) e admite comentários de qualquer usuário que mantenha o cadastro ativo, tanto os usuários comuns quanto os agentes públicos.

Quanto ao termo de uso, o aplicativo pede autorização para ter acesso à câmera e acesso às fotos armazenadas, gravar vídeos, encontrar contatos da agenda pessoal e a localização indicada pelo GPS. A última atualização do aplicativo Colab foi em 2 de setembro de 2019 (versão 5.3.5). Para ajudar na moderação das postagens, cada publicação traz um botão no qual é possível bloquear o usuário ou reportar o que foi exposto, caso desvie da proposta do aplicativo ou do que o usuário entende como adequado.

Quadro 3 - Categorização da iniciativa Colab

\begin{tabular}{|l|l|}
\hline \multicolumn{1}{|c|}{ Dimensões } & \multicolumn{1}{c|}{ Descrição } \\
\hline $\begin{array}{l}\text { Recursos } \\
\text { tecnológicos }\end{array}$ & $\begin{array}{l}\text { Site institucional; aplicativo disponível em Android e } i O S \text {; registro por e-mail pessoal } \\
\text { ou vinculado ao Facebook; cadastro e plataforma para agentes públicos; mapa } \\
\text { atualizado de acordo com o GPS e rede individual com critérios de fiscalização e } \\
\text { qualificações. }\end{array}$ \\
\hline $\begin{array}{l}\text { Modos de } \\
\text { participação on- } \\
\text { line }\end{array}$ & $\begin{array}{l}\text { Publicações de fotos que reportam problemas urbanos; engajamento através de } \\
\text { curtidas, compartilhamentos. }\end{array}$ \\
\hline $\begin{array}{l}\text { Atores } \\
\text { envolvidos }\end{array}$ & $\begin{array}{l}\text { Servidores públicos e indivíduos da sociedade civil. Cada tipo de usuário com cadastro } \\
\text { e interface específicos. }\end{array}$ \\
\hline $\begin{array}{l}\text { Objetivos } \\
\text { políticos }\end{array}$ & $\begin{array}{l}\text { Dar visibilidade para os problemas enfrentados pelo cidadão em sua experiência nas } \\
\text { cidades; caso seja do interesse dos agentes públicos municipais - e tendo a autoridade } \\
\text { pública competência e capacidade - responder as demandas apresentadas. }\end{array}$ \\
\hline $\begin{array}{l}\text { Captação de } \\
\text { recursos }\end{array}$ & $\begin{array}{l}\text { R\$ 4 milhões da Omidyar Network 2017; área de mídias independentes MDIF (Media } \\
\text { Development Investment Fund); US\$ 5 mil de um concurso internacional da New } \\
\text { Cities Foundation; os contratos com as prefeituras variam de 38 a 500 mil reais por } \\
\text { ano, o preço por habitante varia entre R\$ 0,40 e R\$ 1,50. }\end{array}$ \\
\hline
\end{tabular}

Fonte: Elaboração dos autores.

\subsection{Panela de Pressão}

A plataforma Panela de Pressão foi desenvolvida pela equipe da Rede Nossas Cidades com o objetivo de ser um canal de mobilização para pressionar governantes e gestores públicos em decisões de interesse público. A Rede Nossas Cidades reúne coletivos municipais espalhados em várias cidades do Brasil. As petições on-line são a funcionalidade mais destacada na plataforma, embora a organização trabalhe também com outros recursos a depender de cada campanha. 
A ideia é simples: criar uma estratégia que envolva recursos on-line e off-line para defender os interesses da cidadania em questões que eventualmente estejam na pauta de cada cidade. Os cidadãos podem demonstrar apoio simplesmente clicando em um botão ou participar de atividades mais custosas em termos de tempo e esforço, a exemplo de buscar apoio de outros cidadãos ou manifestar-se contra os gestores públicos.

A plataforma permite ainda que o cidadão monitore as demandas que são atendidas ou não pelos gestores municipais. Assim, mas também mediante outras ações mais pontuais, o projeto Panela de Pressão contribui para a fiscalização dos agentes políticos e suas atividades públicas.

Figura 5 - Destaques das principais mobilizações do Panela de Pressão.

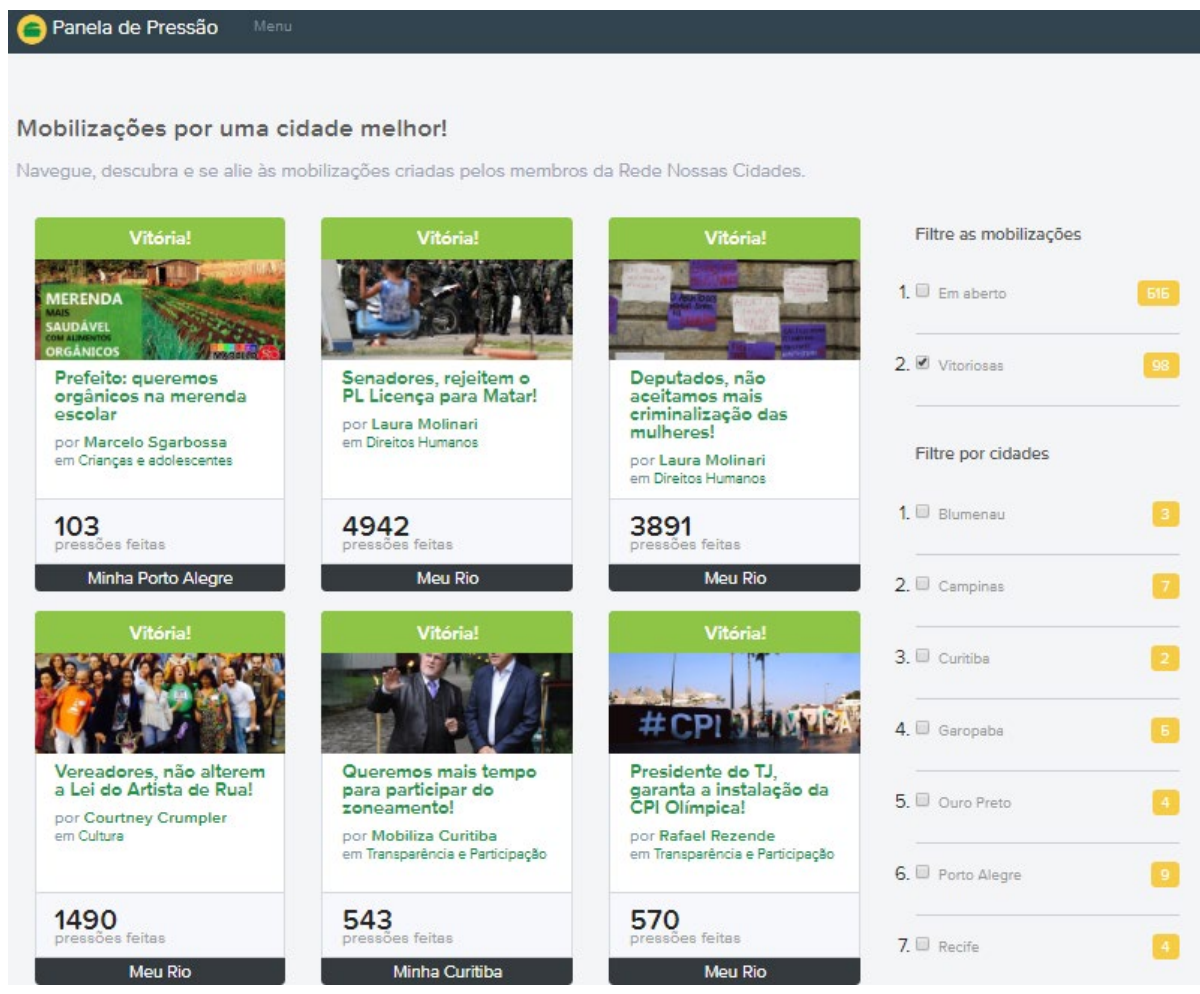

Fonte: Mobilização Panela de Pressão (2019).

Os usuários cadastrados podem fazer publicações, mas estas são moderadas antes da postagem por parte da equipe do Panela de Pressão. Assim, a organização tem algum controle dos empregos dados à ferramenta. Os membros podem enviar fotografias para apresentar todo e qualquer tipo de demanda, como por exemplo, a exigência de alimentos orgânicos nos refeitórios das escolas públicas, melhor asfaltamento nas vias públicas e delegacias da mulher que funcionem $24 \mathrm{~h}$ por dia. 
Toda e qualquer publicação pode ser denunciada e retirada da plataforma se não estiver de acordo com a política expressa no termo de uso. Não é admitido conteúdo que incite o ódio, preconceito social, de raça ou gênero, homofobia, que faça propaganda política partidária, promoção de uma causa privada ou que os administradores entendam que não combina com os objetivos da Rede.

Para iniciar as mobilizações, os integrantes podem telefonar e utilizar os espaços digitais como e-mail, Facebook e Twitter da própria organização. Os gestores da plataforma destacam as ações de maior relevância com a exposição do conteúdo e do quantitativo do engajamento, as vitórias conquistadas através de petições on-line e questões respondidas pelos agentes públicos, bem como identifica a cidade, as iniciativas vinculadas e quantos engajamentos foram realizados. As petições mais populares e com maior número de engajamento tendem a ter mais visibilidade na plataforma.

Quadro 4 - Categorização da iniciativa Panela de Pressão

\begin{tabular}{|c|c|}
\hline Dimensões & Descrição \\
\hline $\begin{array}{l}\text { Recursos } \\
\text { tecnológicos }\end{array}$ & Site institucional; ligação com plataformas da Rede Nossas Cidades. \\
\hline $\begin{array}{l}\text { Modos de } \\
\text { participação on- } \\
\text { line }\end{array}$ & $\begin{array}{l}\text { A vigilância das atividades dos atores políticos; observação e acompanhamento das } \\
\text { políticas públicas; mobilizações para manter contato direto com os governantes e/ou } \\
\text { quaisquer outros tomadores de decisão nas cidades. }\end{array}$ \\
\hline Atores envolvidos & $\begin{array}{l}\text { Indivíduos da sociedade civil com registro no aplicativo e agentes públicos } \\
\text { responsáveis pela tomada de decisão. }\end{array}$ \\
\hline $\begin{array}{l}\text { Objetivos } \\
\text { políticos }\end{array}$ & $\begin{array}{l}\text { Dar visibilidade para os problemas das cidades; mobilizar os concernidos pelas } \\
\text { causas em pauta; monitorar a atividade dos agentes públicos municipais; pressionar } \\
\text { os agentes públicos durante o processo de tomada de decisão. }\end{array}$ \\
\hline $\begin{array}{l}\text { Captação de } \\
\text { recursos }\end{array}$ & Crowdfunding - pessoas físicas podem contribuir com qualquer valor. \\
\hline
\end{tabular}

Fonte: Elaboração dos autores.

Para cada ação proposta existe uma caixa de comentários que é vinculada à conta do Facebook do usuário. É possível estimular o engajamento de outros usuários através de um clique na ação proposta. Todo gestor citado é identificado com nome, foto, cargo e cidade, ações anteriores que envolvem o seu trabalho e a caracterização de ações respondidas por ele ou não. Assim, espera-se que essa pressão sirva como motivação para que o gestor responda as demandas. 


\section{Discussão: as iniciativas de participação não estatal como parte da esfera pública}

As inovações políticas em análise amplificam a esfera pública (HABERMAS, 2003, 2011), considerando que os recursos das plataformas, com características tecnológicas e cultura de uso específicas, desenvolvem novas capacidades de articulação de interesses da cidadania, conforme argumento de Gomes (2011), discussão sobre os temas, mas principalmente a inserção desses interesses diretamente no processo de tomada de decisão.

As organizações escolhidas para o estudo procuram reunir cidadãos, gestores públicos e, em alguns casos, políticos eleitos. As problemáticas são colocadas em cena por iniciativa de cidadãos individuais ou por coletivos da sociedade civil. Apesar de serem plataformas digitais consideravelmente distintas entre si e desenvolvidas por atores não estatais, a participação está aberta a todos os interessados. Portanto, trata-se de mecanismos potencialmente inclusivos, por mais que tenhamos sempre que considerar os efeitos da falta de acesso à internet e as limitações impostas pela falta de habilidade para realizar as atividades participativas demandadas pelas iniciativas.

Um ponto fundamental para o campo da participação política on-line diz respeito à conexão com o sistema político, o modo como os inputs dos cidadãos são considerados no processo de tomada de decisão (MEDAGLIA, 2012). A Colab tem como estratégia aproximar-se dos gestores públicos, até mesmo para vender o acesso à plataforma, de modo que estes possam responder diretamente às demandas dos cidadãos.

Por um lado, a plataforma precisa que as publicações dos usuários tenham visibilidade suficiente para que os gestores percebam a plataforma como relevante. Por outro lado, não seria interessante que as demandas apresentadas pelos usuários superassem a capacidade estatal, questionassem as políticas implementadas ou as escolhas dos gestores, uma vez que o modelo de negócio da plataforma depende da decisão de compra por parte do governo municipal.

Trata-se, em geral, de reclamações específicas que as prefeituras têm condições de resolver com relativa celeridade. Nesse sentido, podemos dizer que as pessoas colaboram com a administração municipal ao tempo em que monitoram e informam o problema. Uma vez resolvidos os problemas, a gestão ganha visibilidade positiva.

A Colab como produto permite que prefeituras promovam consultas sobre temas-chave das cidades pelo aplicativo, a fim de legitimar as prioridades dos 
investimentos públicos. Segundo o jornal Meio\&Mensagem (2017), a Prefeitura de Santos destinou R 10 milhões para o orçamento participativo digital, que alcançou mais de 10 mil votos, 32 vezes mais que o modelo tradicional influenciando diretamente na política local. Atualmente a Colab possui função que permite vincular empresas privadas que tenham interesse em associar suas marcas à uma conduta cidadã, propondo publicidade de empresas privadas através de anúncios no aplicativo e desenvolvendo um sistema de crowdfunding para resolver problemas.

A plataforma Mudamos, por sua vez, trabalha com a ideia de instrumentalizar a sociedade brasileira para usar um dispositivo constitucional que permite a proposição de projetos de lei de iniciativa popular mediante a criação de um sistema seguro para a coleta de assinaturas por meio de aplicativo próprio para celular. $\mathrm{O}$ entendimento é que uma das grandes dificuldades para a apresentação desse tipo de projeto de lei sempre foi o trabalho para a coleta de assinaturas. Espera-se que essa dificuldade seja mitigada, mas os efeitos práticos da iniciativa ainda precisam ser devidamente avaliados.

Por ter como modo de financiamento um prêmio do Google de R\$ 1,5 milhão, a plataforma não vende serviços para os órgãos públicos ou muito menos para seus usuários, o que dá relativa autonomia em sua atuação. Desde a concepção do aplicativo, nenhum projeto de lei foi aceito em formato digital devido à dificuldade de processamento desse tipo de projeto por parte do legislativo brasileiro que acumula as propostas de projetos de lei de iniciativa popular.

O Panela de Pressão, por outro lado, tem como principal estratégia o enfrentamento, o constrangimento, a pressão aos gestores públicos municipais no sentido do respeito aos interesses da cidadania. O financiamento da plataforma, considerando o que conseguimos apurar, é por crowdfuding. A iniciativa, portanto, trabalha com temas e com estratégias que os cidadãos considerem importantes $\mathrm{o}$ suficiente para fazer doações. A vantagem é que a plataforma pode adotar discursos e ferramentas de enfrentamento sem se preocupar em manter relações cordiais com os gestores ou com eventuais financiadores.

Considerando o campo de estudos da democracia digital, defendemos a importância do estudo do desenho organizacional para nos ajudar a entender melhor algumas variáveis estruturais que explicam a configuração, o design, as estratégias das iniciativas. Por mais que o presente estudo possa ter falhas ou ausências, gostaríamos de chamar a atenção para esta dimensão das iniciativas. Ao entendermos que os desenhos 
organizacionais não são neutros, podemos questionar o modo como as escolhas e as variações deles podem influenciar diretamente os resultados da participação política.

Seguindo o argumento de Avritzer (2008), para quem o estudo do desenho institucional é importante para entender as instituições participativas (a saber, orçamentos participativos, conselhos e planos diretores municipais), defendemos que o estudo do modo como as iniciativas da sociedade civil e de empresas se organizam pode nos ajudar a entender as escolhas políticas (agendas, estratégias, argumentos, atores convidados) e técnicas (interfaces, design gráfico, modo de recebimento e organização dos inputs dos cidadãos) das iniciativas.

Por fim, entendemos que as iniciativas Mudamos, Colab e Panela de Pressão, ao passo que promovem inovações relevantes no uso da tecnologia, mas também na articulação política entre cidadãos e atores estatais, convocam um olhar para o modo como a sociedade pode participar da política, não apenas através dos canais institucionais ou da deliberação pública, mas criando modos inovadores de promover a articulação entre o mundo da vida com o sistema político. Em algumas situações com a participação de novas formas de organização da sociedade civil e até mesmo de empresas.

Em busca de promover visibilidade às pautas, mas também para a promoção da visibilidade da própria iniciativa, todas elas procuram criar estímulos para que os usuários façam publicações relacionadas em plataformas mais populares, a exemplo de Facebook e Twitter. Essa preocupação é estratégica para as iniciativas aqui estudadas, mas pode também criar condições para a articulação com a esfera pública mais ampliada. Esse movimento é expresso tanto no design, nas ferramentas e soluções tecnológicas, quanto no discurso de motivação para a participação política em outros espaços, bem como no modo como são encaminhadas as demandas para o respectivo ator estatal que tem poder administrativo, político ou jurídico para transformar essa demanda em ação e em solução.

Como adequar a motivação do cidadão a estratégias politicamente eficientes, contudo, é algo ainda a ser estudado. Ressaltamos que somente a existência de canais entre a cidadania e a esfera da decisão política não pode ser tomada como influência direta na decisão final. É necessário considerar como as opiniões dos cidadãos manifestadas nos aplicativos são processadas pelo sistema político, em especial no processo de tomada de decisão (BARROS, 2016). A meta é o cidadão deixar de ser 
usuário-cliente e ter condições e reconhecimento como protagonista na solução de problemas que dizem respeito à dimensão política da vida.

\section{Referências}

ASSINATURA Mudamos, Voto Limpo. 2019. Disponível em:

https://www.mudamos.org/temas/pelo-fim-da-compra-de-apoio politico/plugins/peticao. Acesso em 20 de dez. de 2019.

AVRITZER, Leonardo. Instituições participativas e desenho institucional: algumas considerações sobre a variação da participação no Brasil democrático. Opinião Pública, v. 14,. N. 1, p. 43-64, 2008.

BARROS, Samuel. Os desafios das consultas públicas online: lições do Marco Civil da Internet. Liinc em Revista, vol. 12, $\mathrm{n}^{\circ}$. 1, 2016.

BRANDSEN, T.; HONINGH M. Distinguishing different types of co-production: A conceptual analysis based on the classical definitions. Public Administration Review, v. 76, n. 3, p. 427-435, 2016.

COLAB App Store. Disponível em: https://www.colab.re/. Aplicativo sistema Android disponível em:

https://play.google.com/store/apps/details?id=thirtyideas.colab_android\&hl=pt_BR. Acesso em 10 de jun. 2019. Sistema iOS disponível em:

https://apps.apple.com/br/app/colab/id609666061. Acesso em: 10 jun. de 2019.

D'ANDRÉA, C. Pesquisando plataformas on-line: conceitos e métodos. Salvador: EDUFBA, Coleção Cibercultura, 2020.

DAHLBERG, L. Re-constructing digital democracy: An outline of four 'positions. New Media \& Society, v. 13, n. 6, p. 855-872, 2011.

DOIMO, Amanda Cristina. Hackerspaces e cultura hacker: reflexões sobre tecnologia e democracia. 2019. (104 p.). Dissertação (mestrado) - Universidade Estadual de Campinas, Faculdade de Ciências Aplicadas, Limeira, SP.

FARIA; RIBEIRO, U. C. Desenho institucional: variáveis relevantes e seus efeitos sobre o processo participativo. In: PIRES, R. (Org.). Efetividade das instituições participativas no Brasil: estratégias de avaliação. 1 ed. Brasília: IPEA, 2011, v. 7, p. 125-136.

GOMES, W. Participação política on-line: questões e hipóteses de trabalho. In: MAIA, R.C.M; GOMES, W.; MARQUES, F.P.J.A. (Org.). Internet e participação política no Brasil. 1 ed., Porto Alegre: Sulina, 2011, p. 19-46.

GOMES, Wilson. Esfera Pública Política e Comunicação em Direito e Democracia de Jürgen Habermas. In: GOMES, W.; MAIA, R. C. M. Comunicação e Democracia: problemas \& perspectivas. São Paulo: Paulus, 2008, p. 69-116. 
GRONLUND, A. e-Democracy: in Search of Tools and Methods for Effective

Participation. Journal of Multi-Criteria Decision Analysis, v. 12, 2003, p. 93-100.

HABERMAS, Jürgen. Mudança Estrutural da Esfera Pública: investigações quanto a uma categoria da sociedade burguesa. Rio de Janeiro, RJ: Tempo Brasileiro, 2003, 98p.

HABERMAS, Jürgen. Direito e Democracia: entre facticidade e validade, volume II. Rio de Janeiro, RJ: Tempo Brasileiro, 2011, 352p.

LUVIZOTTO, Caroline Kraus. Cidadania, ativismo e participação na internet: experiências brasileiras. Comunicação e Sociedade, v. 30, p. 296-312, 2016.

MARCONDES, Pyr. Startup Colab.re que fiscaliza serviços públicos recebe R \$ 4 milhões. Meio \& Mensagem, 2017. Disponível em:

https://www.proxxima.com.br/home/proxxima/noticias/2017/05/18/startup-colab-reque-fiscaliza-servicos-publicos-recebe-r-4-milhoes.html. Acesso em: 22 dez. 2019.

MEDAGLIA, Rony. E-Participation research: Moving characterization forward (20062011). Government Information Quarterly, v. 29, n. 3, p. 346-360, 2012.

MENDONÇA, Ricardo; PEREIRA, Marcus. Democracia digital e deliberação online: um estudo de caso sobre o VotenaWeb. In: IV CONGRESSO Latino AmericanoLATINO-AMERICANO DE OPINIÃO PÚBLICA. 4., 2011. Anais [...]. Belo Horizonte, 2011, p. 2-25.

MITOZO, Isabele. O Portal e-Democracia e suas potencialidades: avanços e desafios de uma ferramenta de participação legislativa (Entrevista com Cristiano Ferri de Faria). Revista Compolítica, v. 4, n. 2, p. 185, 2014.

MUDAMOS. Disponível em: https://www.mudamos.org/. Aplicativo sistema Android disponível em:

https://play.google.com/store/apps/details?id=org.mudamos.petition\&hl=pt_BR.

Sistema iOS disponível em: https://apps.apple.com/br/app/mudamos/id1214485690?.

Acesso em: 10 de jun. 2019.

MUDAMOS App Store. Disponível em: https://apple.co/2RzZddq. Acesso em: 06 de nov. de 2019.

MOBILIZAÇÃO Panela de Pressão. 2019. Disponível em:

$<$ http://paneladepressao.nossascidades.org >. Acesso em 22 de dez. de 2019.

NOVECK, Beth Simone. Wiki government: How technology can make government better, democracy stronger, and citizens more powerful. Brookings Institution Press, 2009.

O'REILly, T. Government as a Platform. Innovations. volume 6, number 1, 2010, p. 13-35.

PANELA de Pressão. Disponível em: http://paneladepressao.nossascidades.org. Acesso em: 14 jun. 2019. 
PINHO, Maria. Democracia Digital, Governos e Dados Abertos: O estado da arte sobre Governo Aberto e Dados Abertos Governamentais, com um estudo de caso do governo federal brasileiro. Universidade Federal da Bahia (Dissertação de Mestrado), 2019.

PROJETOS de Lei Mudamos. 2019. Disponível em: <

https://www.mudamos.org/projetos>. Acesso em 20 de dez. de 2019.

ROSSETTO, Graça Penha Nascimento; CARREIRO, Rodrigo. Democracia digital e sociedade civil: uma perspectiva do estado atual no Brasil. Comunicação \& Sociedade, v. 34, n. 1, p. 273-296, 2012.

SANTOS, José Antônio Pedro; NETO, Jorge da Silva Correia; SOUZA, Ellen. Funcionalidades, Características e Limitações das Plataformas de Participação e Colaboração: uma análise comparativa. GESTÃ̃O. Org: Revista Eletrônica de Gestão Organizacional, v. 15, p. 147-156, 2017.

SILVA, Alexandre Campos; POLICARPO, Clayton. Rede social, colaboração e mobilidade: o caso do aplicativo urbano Colab no Brasil. RUA, v. 20, n. 2, p. 18-31, 2014.

SRNICEK, Nick. Platform Capitalism. Cambridge, UK; Malden, MA: Polity Press, 2017.

\footnotetext{
${ }^{a}$ Docente permanente e orientador do Programa de Pós-Graduação em Comunicação e Cultura Contemporâneas (PósCom-UFBA). Pesquisador no Instituto Nacional de Ciência e Tecnologia em Democracia Digital (INCT.DD).

${ }^{\mathrm{b}}$ Doutoranda e mestre do Programa Comunicação e Cultura Contemporâneas pela Universidade Federal da Bahia (UFBA). Integrante do Instituto Nacional de Ciência e Tecnologia em Democracia Digital (INCT.DD), desempenha pesquisas no grupo Comunicação, Internet e Democracia (CID/UFBA). Graduada em Comunicação Social com habilitação em Relações Públicas pela Universidade Salvador (UNIFACS), 2016, realizou pesquisas no grupo de Comunicação, Desenvolvimento e Discursos (Com2D/UNIFACS) e é graduanda em Serviço Social pela UFBA. Possui experiência na área de comunicação digital e tecnologia organizacional.
} 